\title{
Tracking B-31 iceberg with two aircraft-deployed sensors
}

\author{
D. H. Jones and G. H. Gudmundsson \\ British Antarctic Survey, High Cross, Madingley Road, Cambridge, UK \\ Correspondence to: G. H. Gudmundsson (ghg@ bas.ac.uk) \\ Received: 20 May 2014 - Published in Nat. Hazards Earth Syst. Sci. Discuss.: 10 July 2014 \\ Revised: 15 December 2014 - Accepted: 8 May 2015 - Published: 16 June 2015
}

\begin{abstract}
Icebergs are a natural hazard to maritime operations in polar regions. Iceberg populations are increasing, as is the demand for access to both Arctic and Antarctic seas. Soon the ability to reliably track icebergs may become a necessity for continued operational safety. The temporal and spatial coverage of remote sensing instruments is limited, and must be supplemented with in situ measurements. In this paper we describe the design of a tracking sensor that can be deployed from a fixed-wing aircraft during surveys of Antarctic icebergs, and detail the results of its first deployment operation on iceberg B-31.
\end{abstract}

\section{Introduction}

Icebergs represent an environmental hazard to shipping and fixed marine structures, particularly in the circumpolar Antarctic waters and the North Atlantic, near to Greenland, where iceberg density is greatest (Gentleman et al., 1994). Since 1850 there have been 611 recorded collisions between icebergs and ships (Hill, 2005). This threat to maritime safety is expected to worsen as demand for access to these regions increases. Figure 1 shows that the number of tourists visiting Antarctica by ship has been rising since records begin in 1992, up until the global economic crisis in 2007, and then subsequent to the recovery in 2011. Figure 2 shows that exploration licenses for drilling for petroleum resources off Greenland have been rapidly increasing, in part due to the diminishing Arctic sea ice and corresponding effects on ease of access for maritime logistics. Furthermore global warming and its disproportionate impact on polar regions have led to increased iceberg populations (Smith et al., 2013), though this may in turn be offset by the increased melt rates of icebergs due to the warming surface sea temperatures. Thus the threat of icebergs colliding with maritime infrastructure is rising, and the ability to track icebergs reliably could in future provide a valuable additional source of information for shipping operations in polar waters.

\section{Existing monitoring strategies}

Satellite-based optical sensors produce high-resolution images of icebergs that are used for iceberg tracking, but these are unable to penetrate cloud cover and are dependent on solar illumination. Synthetic array radar (SAR) satellite performance is independent of solar illumination and generally unaffected by cloud cover (McCandless and Jackson, 2003); however, the spatial coverage of these sensors is limited, frequently resulting in poor temporal resolution. As a result, the database of known locations of large icebergs, as maintained by the US National Ice Center (NIC), is typically updated every 20 days (Stuart and Long, 2011).

The microwave emissivity of a material is affected by its atomic structure, and thus can be used to differentiate between sea and ice from satellite based sensors. Passive microwave radiometry sensors onboard satellites have been used to track large icebergs (Phillips and Laxon, 1995) and are still used to track the extent of sea ice e.g. Bliss and Anderson (2014). Another satellite-based sensor that is still used for iceberg tracking is a microwave scatterometer. This was first demonstrated in Stuart and Long (2011) with data from the QuikSCAT satellite - large icebergs appear as highbackscatter targets surrounded by lower-backscatter sea water or sea ice. QuikSCAT ceased operations in 2009, but the technique is still used with data from the Advanced Scatterometer (ASCAT) satellite and the recently launched OceanSat-2 scatterometer (OSCAT). This supplements the NIC database with monthly position updates for large icebergs. 


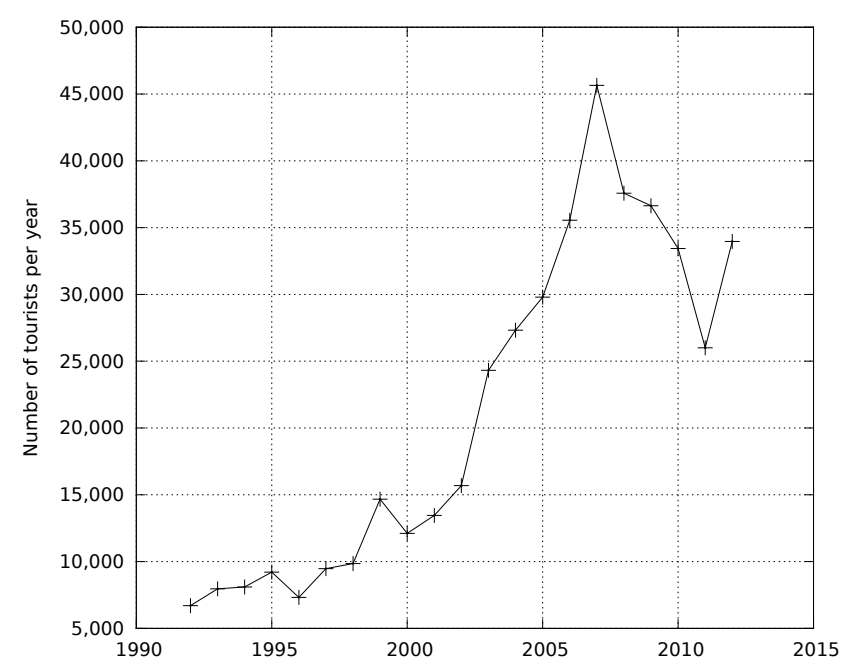

Figure 1. Number of tourists visiting the Antarctic by ship (IAATO, 2013).

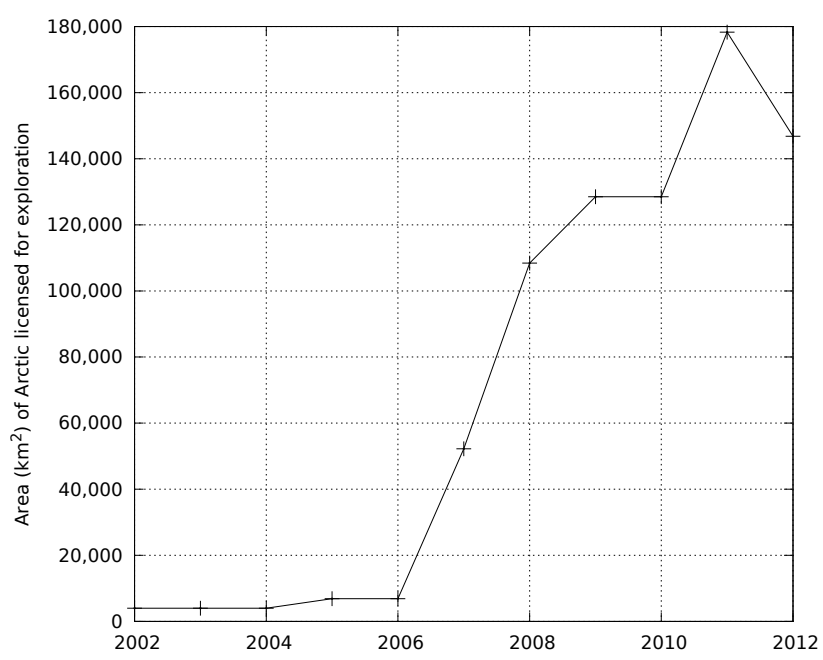

Figure 2. Area of Arctic licensed for oil exploration in Greenland, derived from NUNAOIL annual report 2012 (Olsen, 2012).

The Polar View website (www.polarview.aq) maintained by the British Antarctic Survey provides a useful portal for polar operators to access SAR images from the Sentinel-1 SAR satellite operated by the European Space Agency. This satellite has been launched recently, and replaces the SAR coverage provided by Envisat until 2012.

The limited temporal coverage of satellite-based sensors, the dependence of optical sensors on clear skies and solar illumination, and the inability for microwave-based scatterometer sensors to resolve small and medium sized icebergs means that a supplementary method for determining iceberg location is sometimes necessary.

The Newfoundland and Labrador tourism department uses reported visual sightings in conjunction with RADARSAT-2 imagery in order to maintain a separate database of iceberg locations in the region.

An alternative to visual sightings and remote sensing is the use of tracking buoys.

\section{Ice tracking buoys}

The ability to instrument large expanses of sea ice or iceberg fields from fixed-wing aircraft has been of interest to military and maritime scientists for 44 years. In 1970 and 1971 the US coastguard tested an aircraft-deployed ice penetrator designed to measure ice thickness. The military potential saw the US Naval Ordnance Laboratory and Sandia labs test larger ice penetrators in 1973 (Young, 1974). The first operational ice tracking sensors were developed for ice pack drifting experiments and deployed in 1978 (Brown and Kerut, 1978). These Air Droppable Remote Access Measurement System (ADRAMS) buoys were shaped like a $22^{\prime \prime}$ diameter sphere and adapted for deployment from a Hercules aircraft. Development of systems subsequent to ADRAMS has been in response to increasing air safety regulations, the improvement of battery technologies and the availability of more advanced and compact electronics.

Current commercial systems are made by Canatec and MetOcean. The MetOcean Compact Air-Launched Ice Beacon (CALIB) buoy is currently in use by the Canadian Ice Service and has been used in the past as part of the International Ice Patrol (IIP).

The CALIB is a commercially available tracking device that can be dropped from a fixed-wing aircraft. CALIB buoys have been used to track icebergs with some success.

The IIP first tested them in 2003 and succeeded in tracking an iceberg for 13 days (Hicks, 2003); however, trials in 2007 (two buoys) and 2011 (one buoy) failed with no data transmissions received (Hicks, 2011). More success has been had deploying CALIB by hand: a study by the Canadian Fisheries and Oceans in 2009 deployed 4 CALIBS, each lasted for approximately lasted for 2 months. A follow-up deployment in 2011 saw 4 CALIBS transmit data for $4-5$ days (Peterson and Prinsenberg, 2011). The short lifespan of these buoys may be reflecting the dynamic and unstable nature of their target, although the deployment profile is not robust to different snow conditions. The CALIB is designed to partially penetrate the snow pack and stand upright. If dropped from an aircraft, the depth of penetration depends on the density, viscosity and depth of the snow coverage, so the CALIB may not penetrate sufficiently deep to remain vertical, or bury itself too deep such that the antennas are buried.

In place of iceberg trackers, the IIP now routinely supplements the remote sensing data sets with measurements from the World Ocean Circulation Experiment (WOCE) ocean buoys (Murphy et al., 1996). The IIP typically deploys 1215 of these buoys into the Labrador Sea each year. These buoys are deployed from aircraft as part of the iceberg survey 
missions, or from ship vessels of opportunity. The trajectory measured by each buoy is then used as the basis of a model for predicting iceberg trajectories that year.

Helicopters have been used on occasion to instrument icebergs with tracking devices (Orheim, 1980; Prinsenberg et al., 2012; Gladstone, 2001), see Fig. 3. However, their limited range (for instance, the Bell 206 in Fig. 3 has a maximum range of $702 \mathrm{~km}$, compared to the $1427 \mathrm{~km}$ of a Twin Otter) and payload capacity (635 kg compared to $1940 \mathrm{~kg}$ ) make them unsuitable for any operations beyond the proximity of a large supporting infrastructure. There are also safety concerns when instrumenting smaller, less stable icebergs (Weeks and Mellor, 1977).

If a fixed-wing aircraft had the same ability to instrument icebergs, then the advantages of their increased range, availability and operation costs will allow significantly more icebergs to be instrumented. Furthermore, it would be possible to integrate iceberg instrumentation deployment within existing iceberg survey flights.

\section{Aircraft Deployable Ice Observation System (ADIOS)}

Over the last 3 years we have developed and tested an aircraft-deployable sensor for instrumenting glaciers (Jones and Gudmundsson, 2013). This enabled us to instrument heavily crevassed and otherwise inaccessible glaciers. A subsequent extension of this programme has been to investigate the effectiveness of ADIOS for installing tracking devices on icebergs.

Here we briefly discuss the constraints and ultimate design of ADIOS. See Jones and Gudmundsson (2013) for a more complete description.

\subsection{Design constraints}

In order to minimise costly and time intensive changes to the aircraft platform, an ADIOS is deployed from a standard sonobuoy launch tube mounted $45^{\circ}$ to the aircraft floor. This restricts the diameter of the device at the point of deployment to that of the tube. Also the clearance between the launch tube and the interior aircraft cabin roof limits the length of any component of an ADIOS prior to being installed in the launch tube (see Fig. 4).

As these devices are dropped on otherwise inaccessible icebergs, they have to be considered disposable, which places constraints on both the cost and the environmental impact of the design.

The obstacles to installing sensors on icebergs apply equally to the challenge of retrieving their data locally. Instead an ADIOS must transmit its data to remote servers via a satellite link. Unlike a sonobuoy, which can rely on flotation to ensure its communications antenna is vertical and persists above the surface, this sensor must have a controlled impact

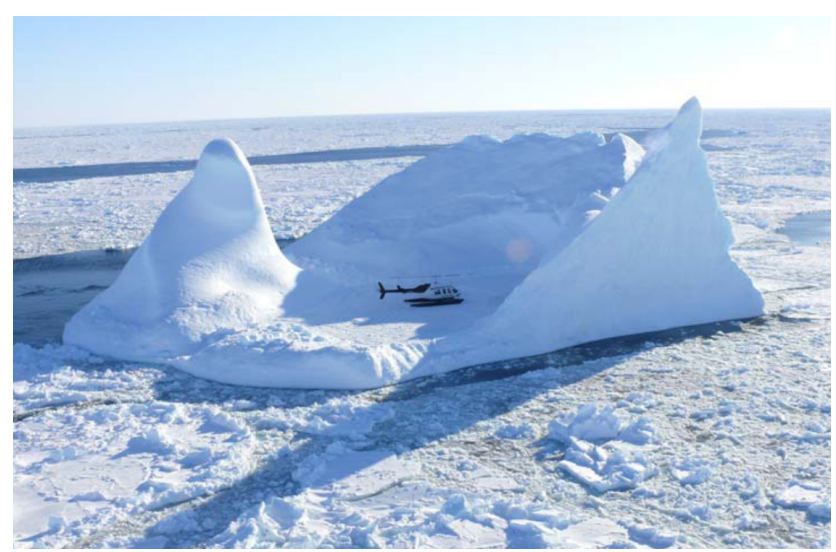

Figure 3. Helicopter landed on iceberg for tracker deployment. Iceberg between Makkovik and Hopedale, Canada. Bell 206L helicopter, fuselage length $10.13 \mathrm{~m}$. Image courtesy of S. Prisenberg (Prinsenberg et al., 2012).

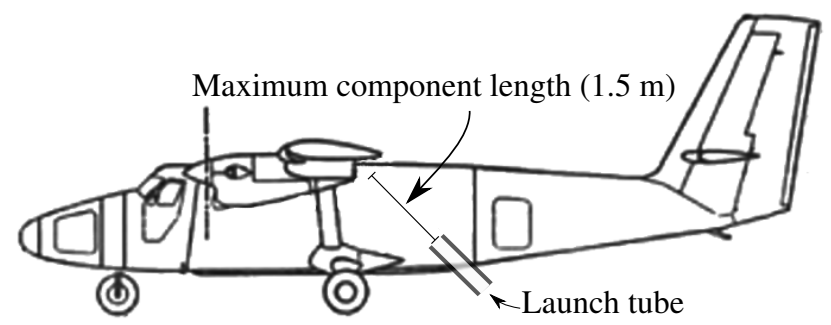

Figure 4. Twin Otter aircraft fitted with sonobuoy launch tube.

angle and speed in order to set its ultimate orientation and depth within the snow. These criteria, in conjunction with local snow accumulation rates, will determine the upper limit of the lifetime of the ADIOS.

The aforementioned size constraints also limit the power source. An effective solar panel or wind turbine will not fit through the launch tube, so the payload has to be powered by a primary battery. In turn this restricts the electronics to consist of only low-power components. The capacity of the power source and the power consumption of the payload will be a limit on the effective duration of the operation of the device.

The ADIOS is designed to partially penetrate the snow, leaving a mast protruding vertically from the surface. The device needs to impact the iceberg with sufficient force so as to partially bury itself even in dense snow conditions. This in turn means the ADIOS will rapidly decelerate after impact. The payload has to be resilient to large deceleration forces and survive the impact intact.

In order to ensure the ADIOS is safe to deploy from an airborne platform, the trajectory of the device after deployment needs to maximise separation from the aircraft as fast as possible. The slowest operational speed of the aircraft we use in this programme is $50 \mathrm{~m} \mathrm{~s}^{-1}$, meaning the device is dropped 
into an airstream of an equivalent velocity. Thus, whilst the device is within proximity of the aircraft it has to have a small aerodynamic profile in order to prevent the airstream, or turbulence under the aircraft, from deflecting the ADIOS back towards the aircraft.

\subsection{ADIOS design}

The ADIOS is $2.5 \mathrm{~m}$ long and consists of a slender $1.5 \mathrm{~m}$ mast, a wider payload compartment and a solid aluminium nose cone (see Fig. 5). The mast and payload compartment are manufactured from poly-propylene, chosen for its impact strength in cold environments. The remaining components are manufactured from aluminium.

In order to ensure that, after impacting with the snow, the payload compartment is subsurface whilst leaving the antenna mast protruding above the surface, four snow brakes are mounted at the top of the compartment. Once the device is buried to a depth of $1 \mathrm{~m}$, these snow brakes effectively increase the surface area by a factor of 4 , and correspondingly its drag in the snow. These snow brakes fold forward and fasten closed during deployment, so as to fit through the launch tube and minimise their aerodynamic effects whilst in proximity to the aircraft. When the device is clear of the aircraft they are released and locked open. The size and shape of these brakes is a tradeoff between their adverse aerodynamic qualities and their ability to stop the device burying to too great a depth.

Without some form of parachute to provide stabilising drag, during free fall the ADIOS will oscillate about its centre of pressure and the horizontal velocity of the device will be largely sustained. Both effects prevent the device from impacting with the ground at $90^{\circ}$. However, parachutes can also introduce payload oscillations due to the irregular and fluctuating airflow conditions around and through the surface of the canopy. In the case of solid flat circular parachutes, the airflow separates from the leading edge of the hemisphere in alternating vortices. Dynamic stability is achieved by controlling this airflow with a more advanced canopy shape adapted from the Mars Viking lander parachute (Gillis, 1973).

\subsection{Design testing}

Over the last 2 years we have conducted design trials in a vertical wind tunnel and from flights local to two Antarctic stations. These trials were used primarily to improve the design stability and the depth to which each ADIOS unit buried itself. By refining the parachute design, snow brake design and the centre of gravity we were able to ensure each ADIOS unit impacts with the surface within $10^{\circ}$ of vertical and $20 \mathrm{~cm}$ of the specified $1 \mathrm{~m}$ depth. The final design used a parachute size that set the terminal velocity of the ADIOS at $42 \mathrm{~m} \mathrm{~s}^{-1}$.

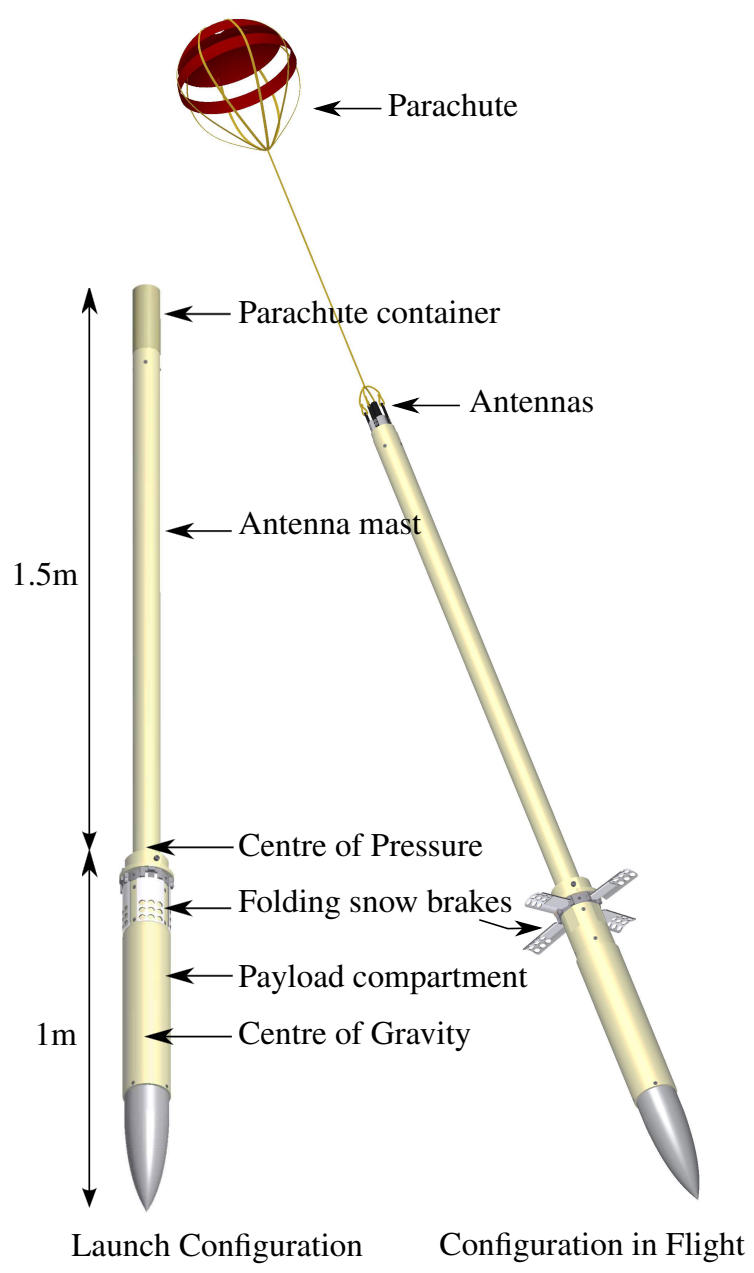

Figure 5. ADIOS design.

\subsection{Limitations}

The ADIOS is designed to stand upright within a snow pack at least $1 \mathrm{~m}$ deep. The majority of Antarctic icebergs travel counter-clockwise around the perimeter of the continent, and accumulate in the Weddell Sea. They are then typically propelled into the Scotia Sea along a northward corridor, until they enter the Antarctic Circumpolar Current (Stuart and Long, 2011). Until they cross $66^{\circ} \mathrm{S}$ the average iceberg surface mass balance is positive. Thus Antarctic tabular icebergs are likely to have sufficient snowpack for instrumentation by the ADIOS.

The trajectory of the ADIOS is predictable, as is the effects of any wind acting on it during descent. As a result, during the trial deployments we were able to consistently drop an ADIOS into a $10 \mathrm{~m}$ square area - icebergs with a smaller surface area are not suitable targets for instrumentation by an ADIOS. Further improvements are hoped to be gained by means of an electronic targeting display undergoing trials in 2014/15. 
The majority of Arctic icebergs form from glaciers on the north-west and south-east quadrants of Greenland. Here snow accumulates between September and May, but then rapidly ablates between June and August (Warren et al., 1998). As a result there is typically little surface snowpack on Arctic icebergs, so these are less appropriate for instrumenting with the ADIOS.

\section{Case study: tracking B-31}

In the following section we demonstrate the capability of the ADIOS for tracking icebergs by presenting data collected by two ADIOS units deployed on iceberg B-31 (see Fig. 7).

In October 2011 a survey flight (Studinger, 2011a) as part of Operation IceBridge (Studinger et al., 2010) discovered a newly formed rift that appeared to span the entire Pine Island Glacier ice shelf. Subsequent flights showed that the rift was not quite complete, but estimated that a complete separation could occur within months (Studinger, 2011b). It would eventually separate to form iceberg B-31 in November 2013, but 11 months before its birth we had an opportunity to deploy two ADIOS units on it.

During the Austral season 2012/13 we deployed 37 ADIOS units on Pine Island Glacier, two of which were west of the rift. This was a unique opportunity to study the birth of an iceberg as well as to evaluate the potential of ADIOS units for iceberg tracking.

The ADIOS units we deployed were fitted with a lowpower single-band GPS receiver. Each unit takes a position fix six times a day, then combines this data with measurements of the GPS accuracy, the unit temperature and the battery voltage. Once a day the data packet is compressed and transmitted over the iridium satellite network. When the available battery power decreases, or GPS reception is no longer possible, the unit enters a low-power mode. In this mode the unit intermittently attempts to transmit the last recorded GPS position. The doppler shift in the iridium transmission, measured by the receiving satellite, makes it possible to determine an approximate location in the event that the GPS is no longer operational. One of the deployed ADIOS units was dropped in a position known to be static. This has been used to calculate the position accuracy in the different operating modes, see Fig. 6. This shows that the GPS position accuracy is in the order of metres, whereas the position accuracy calculated by the iridium transmission is in the order of kilometres.

Since January 2013 we have recorded 4152 position reports from two ADIOS sensors over a period of 406 days (see Fig. 8).

The first 10 months of this data set show B-31 calving from the Pine Island Glacier ice shelf (see Fig. 11). Shortly after its birth, we saw a small part of B-31 (which happened to have an ADIOS unit on it) break off and separate from B31. This can be seen in the increasing separation between
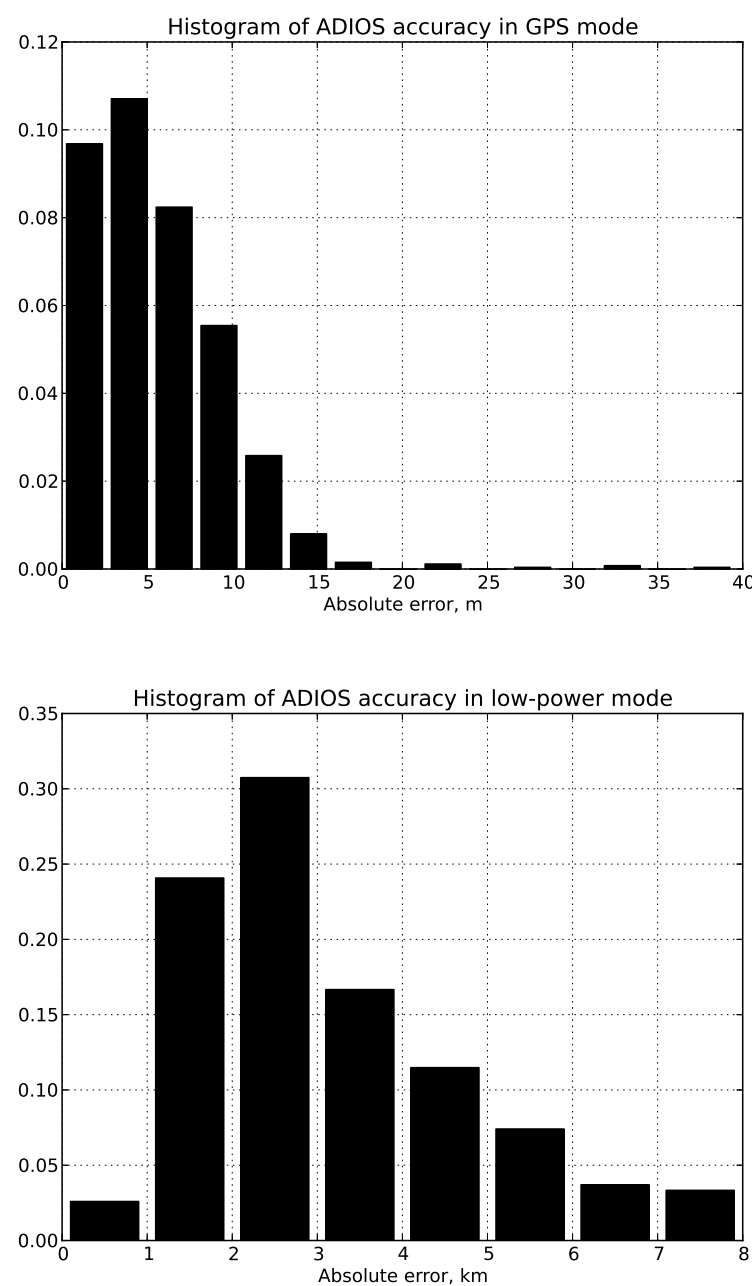

Figure 6. Accuracy of position measurements in GPS and lowpower operating modes.

the two ADIOS units (see Fig. 10). The second, smaller iceberg has become part of the ice mélange surrounding B-31. From the deployment of the ADIOS until the carving of B31 , we recorded $91 \%$ of the expected daily GPS transmissions. The lost transmissions are most likely due to there being a sub-optimal Iridium satellite constellation during the time the ADIOS is trying to transmit.

After the calving of B-31 (November 2013, see Fig. 8) both ADIOS units started to operate intermittently in GPS and low-power operating modes. Figure 9 shows the reported battery voltage and the daily average number of GPS satellites seen by one of the ADIOS units. The sustained battery voltage and continued transmissions suggest that neither the battery or the electronics were damaged. Instead, the drop in the number of GPS satellites seen shortly after indicates that the ADIOS could have become partially buried, tilted, or fallen into a crevasse. Despite this both ADIOS units have continued to intermittently achieve a position fix and transmit it. After the calving event we recorded $29.4 \%$ of the expected 


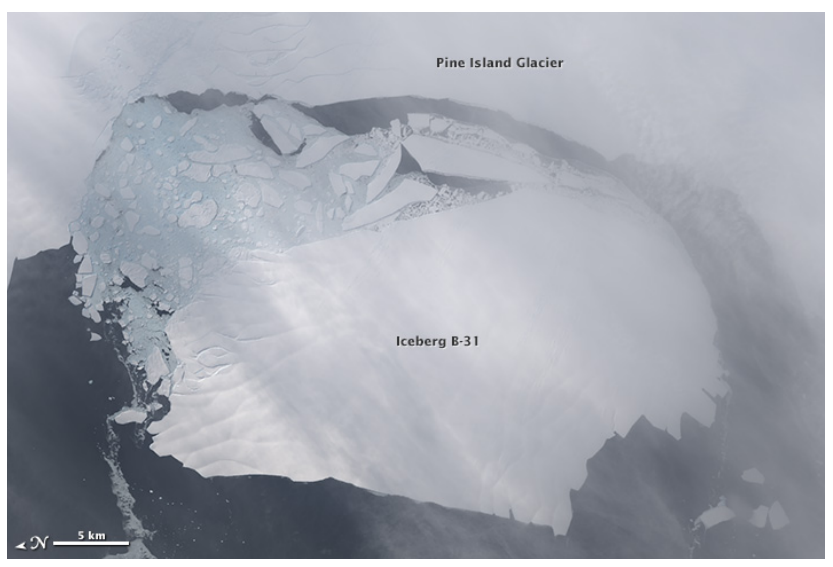

Figure 7. Separation of B31 iceberg from Pine Island Glacier, USGS/NASA. LANDSAT image, 13 November 2013.
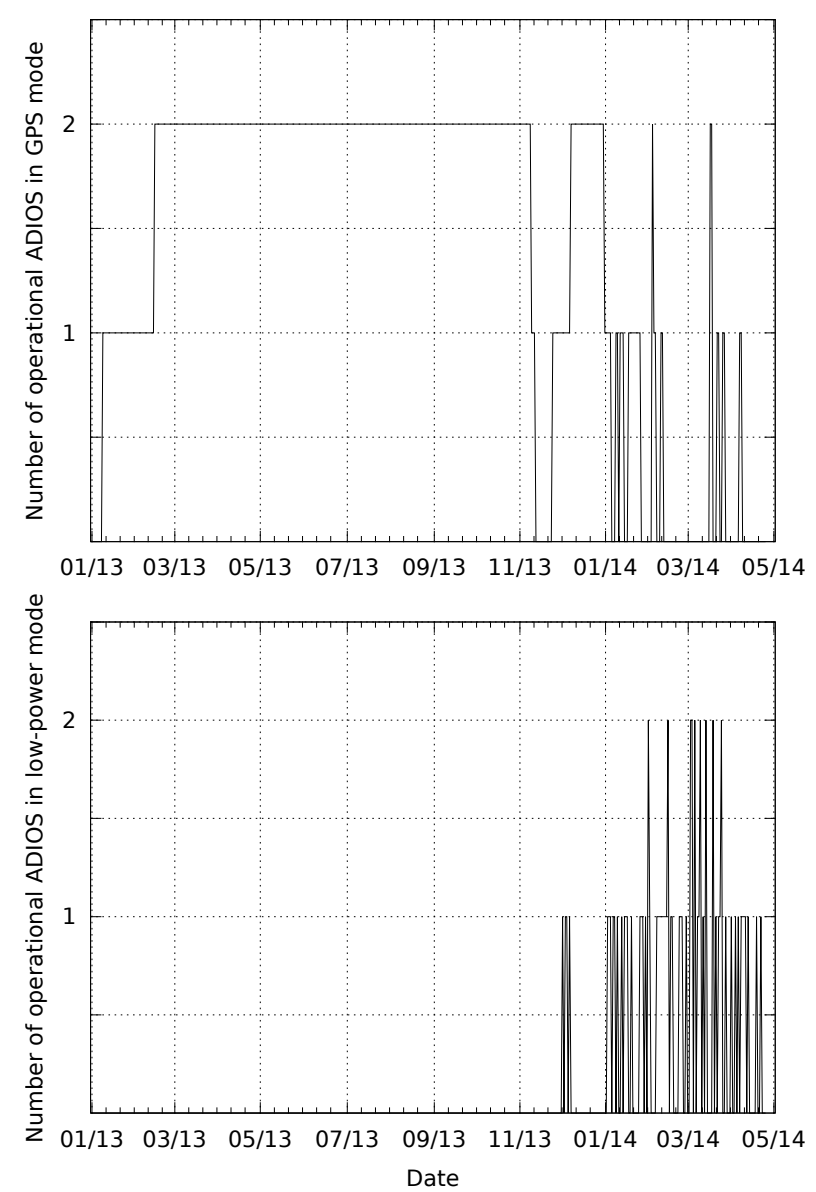

Figure 8. Operational performance of the two ADIOS iceberg tracker units located on iceberg B-31, which calved from the Pine Island Ice Shelf in November 2013.
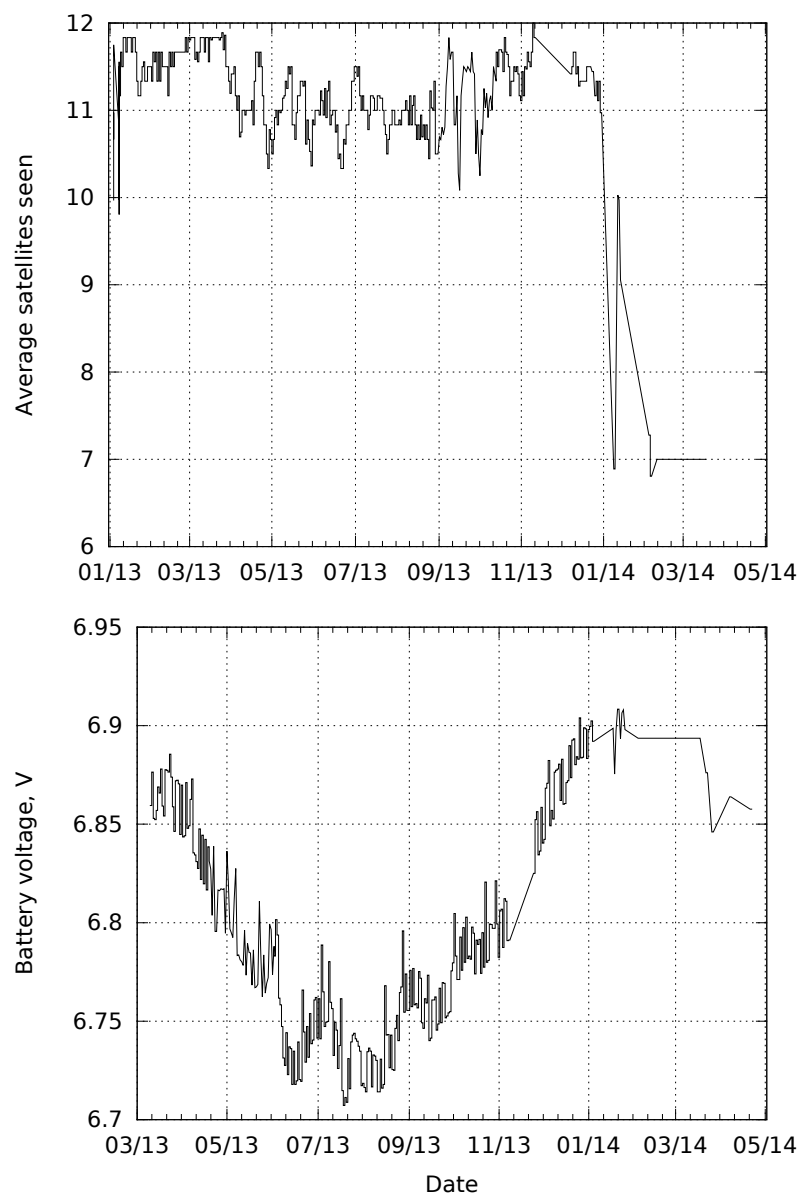

Figure 9. Battery voltage and satellite reception performance of the two ADIOS iceberg tracker units located on iceberg B-31.

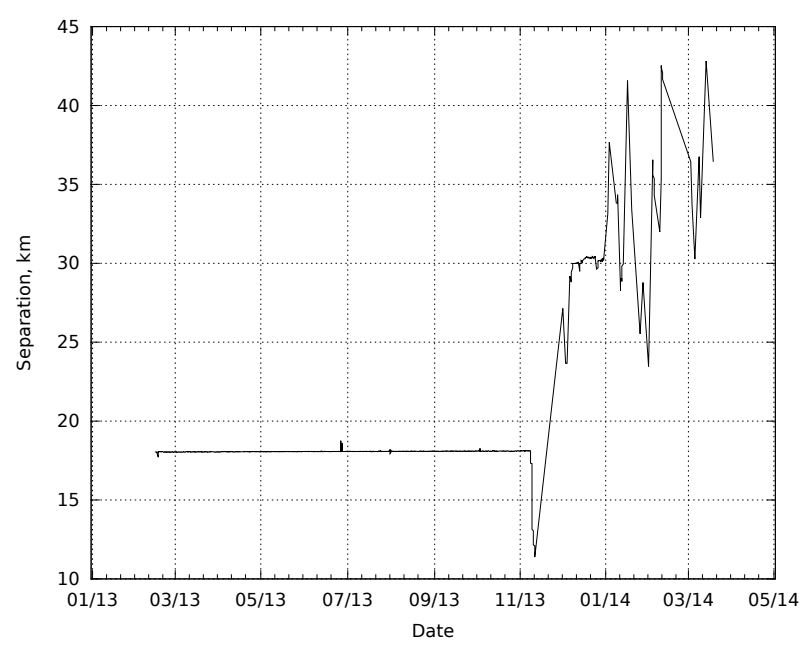

Figure 10. Distance separating each ADIOS unit. 


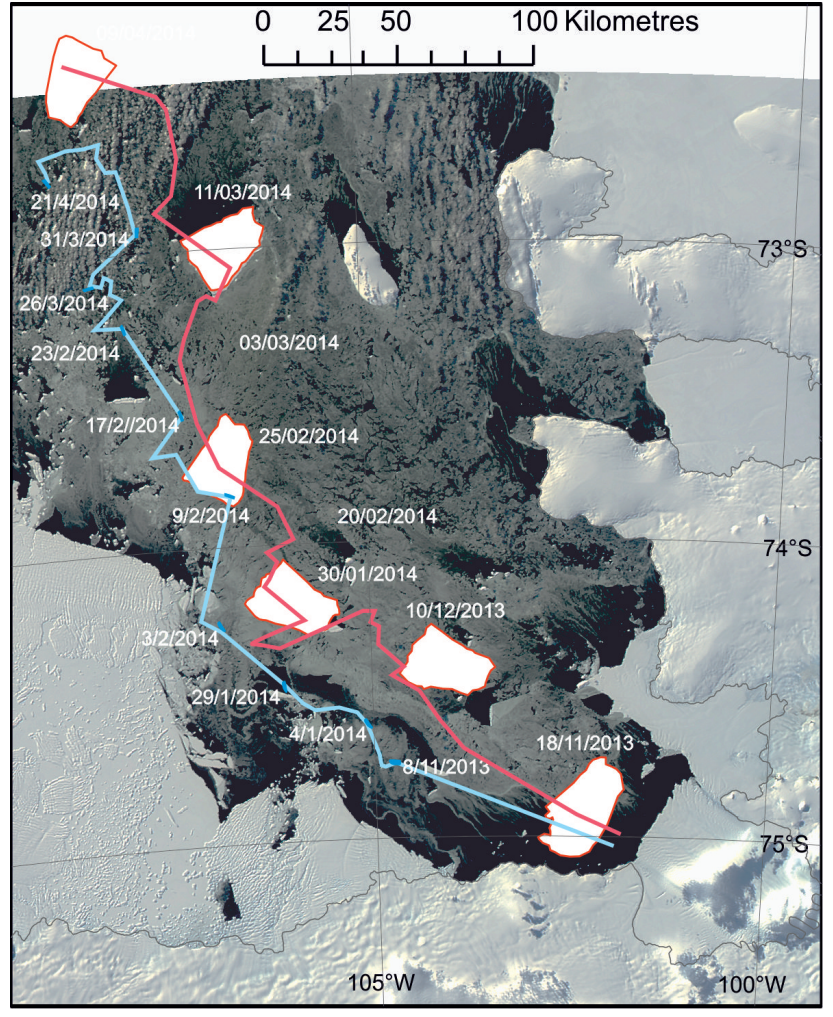

Figure 11. Tracks generated from ADIOS units situated on B-31 iceberg. Iceberg outlines derived from Radarsat2 SAR (courtesy of MacDonald Dettwiler and Associates - MDA Corporation) and MODIS optical (courtesy of NASA) satellite imagery.

daily GPS transmissions, and $21.2 \%$ of the low-power daily transmissions.

\section{Conclusions}

The threat icebergs pose to ships and fixed maritime structures is rising in line with demand for access to Arctic and Antarctic waters. This threat can only be partially mitigated by satellite tracking of icebergs, so there is an increasing demand for the ability to track icebergs with in situ tracking devices.

The Aircraft Deployable Ice Observation System (ADIOS) is particularly appropriate for instrumenting Antarctic icebergs, where there is typically sufficient surface snow for the ADIOS to stand upright in, and can be deployed from fixed-wing aircraft as part of larger iceberg survey missions. This has been demonstrated with the successful tracking of the B-31 iceberg with two ADIOS instruments. The location data these instruments transmitted provided operational support to the I-STAR C expedition during the 2013/14 cruise in the Amundsen sea.
Acknowledgements. This study is part of the British Antarctic Survey Polar Science for Planet Earth Programme. It was funded by The Natural Environment Research Council (NE/I007156/1).

Edited by: B. D. Malamud

Reviewed by: two anonymous referees

\section{References}

Bliss, A. C. and Anderson, M. R.: Arctic sea ice melt onset from passive microwave satellite data: 1979-2012, Arctic, 8, 30373055, 2014.

Brown, W. P. and Kerut, E. G.: Air droppable RAMS (ADRAMS) buoys, AIDJEX Bulletin, 40, 21-29, 1978.

Gentleman, J. F., Whitmore, G. A., Moore, M., and Zwiers, F. W.: Iceberg Paths and Collision Risks for Fixed Marine Structures, Springer-Verlag, New York, 1994.

Gillis, C.: The Viking decelerator system - an overview, in: Proceedings of the 4th Aerodynamic Deceleration Systems Conference, AIAA, 73-442, doi:10.2514/6.1973-442, 1973.

Gladstone, R.: A modelling and remote sensing study of Antarctic icebergs, PhD thesis, University of East Anglia, UK, 2001.

Hicks, M. R.: Report of the International Ice Patrol in the North Atlantic, Bulletin No. 89, CG-188-58, Washington, DC, 2003.

Hicks, M. R.: Report of the International Ice Patrol in the North Atlantic, Bulletin No. 97, CG-188-66, Washington, DC, 2011.

Hill, B. T.: Database of ship collisions with icebergs, available at: www.icedata.ca, last access: July 2014, 2005.

IAATO: IP103: IAATO Overview of Antarctic Tourism: 201213 Season and Preliminary Estimates for 2013-14 Season, ATCM XXXVI, 2013.

Jones, D. H. and Gudmundsson, G. H.: Aircraft Deployable Ice Observation System (ADIOS) for instrumenting inaccessible glaciers, J. Glaciol., 59, 1129-1134, doi:10.3189/2013JoG13J112, 2013.

McCandless, S. W. J. and Jackson, C. R.: Synthetic Aperture Radar Marine User's Manual, Chapter 1, NOAA/NESDIS Office of Research and Applications, available at: http://www. sarusersmanual.com, last access: 1 May 2014, 2003.

Murphy, D. L., Viekman, B., and Channel, C.: New gridded currents for the international ice patrol operations area, OCEANS'96, Prospects for the 21st Century, Conference Proceedings, MTS/IEEE, 2, 613-618, 1996.

Olsen, H. K.: NUNAOIL Annual report, available at: http://nunaoil.gl/fileadmin/nunaoil/pdf/Annual_reports/ NUNAOIL_Annualreport_2012.pdf, last access: 1 May 2014, 2012.

Orheim, O.: Physical charateristics and life expectancy of tabular antarctic icebergs, Ann. Glaciol., 1, 11-18, 1980.

Peterson, I. K. and Prinsenberg, S. J.: Drift of Sea Ice and Icebergs on the Labrador Shelf in 2009 and 2011 from Satellite-Tracked Ice Beacons, Fisheries and Oceans Canada, ISBN 978-1-10023564-6, Technical report, 2011.

Phillips, H. A. and Laxon, S. W.: Tracking of Antarctic tabular icebergs using passive microwave radiometry, In. J. Remote Sens. 16, 399-405, 1995.

Prinsenberg, S. J., Peterson, I. K., Holladay, J. S., and Lalumiere, L.: Labrador shelf pack ice and iceberg survey, March 2011, Can. 
Tech. Rep. Hydrogr. Ocean Sci., 275, 1-55, 2012, http://www.ocean-sci.net/275/1/2012/.

Smith, K. L. J., Sherman, A. D., Shaw, T. J., and Sprintall, J.: Icebergs as unique lagrangian ecosystems in polar seas, Mar. Sci., 5, 269-287, 2013.

Stuart, K. M. and Long, D. G.: Tracking large tabular icebergs using the SeaWinds Ku-band microwave scatterometer, Deep-Sea Res. Pt. II, 58, 1285-1300, 2011.

Studinger, M.: Preliminary Science Flight Report 120105, Operation IceBridge Antarctica 2011, IceBridge Flight Documents, 120105, 2011a.

Studinger, M.: Preliminary Science Flight Report 120122, Operation IceBridge Antarctica 2011, IceBridge Flight Documents, 120122, 2011b.
Studinger, M., Koenig, L., Martin, S., and Sonntag, J. G.: NASA's Operation IceBridge: Using Instrumented Aircraft to Bridge the Observational Gap between ICESat and ICESat-2 Laser Altimeter Measurements, Proceedings of AGU, 2010.

Warren, S. G., Rigor, I. G., and Untersteiner, N.: Snow depth on Arctic Sea ice, J. Climate, 12, 1814-1829, doi:10.1175/15200442(1999)012<1814:SDOASI>2.0.CO;2, 1998.

Weeks, W. F. and Mellor, M.: Some elements of iceberg technology, in: Proceedings of the International Conference on Iceberg Utilization, 1, NASA STI, 1977.

Young, C. W.: Penetration of sea ice by air-dropped projectiles, Engineering in the Ocean Environment, Ocean '74 - IEEE International Conference on, 21-23 August 1974, Halifax, 89-95, doi:10.1109/OCEANS.1974.1161346, 1974. 